\title{
Prevalence of Chlamydophila psittaci infections in a human population in contact with domestic and companion birds
}

\author{
Taher Harkinezhad, ${ }^{1} \dagger$ Kristel Verminnen, ${ }^{1}$ Marc De Buyzere, ${ }^{2}$ \\ Ernst Rietzschel, ${ }^{3,4}$ Sofie Bekaert ${ }^{1}$ and Daisy Vanrompay ${ }^{1}$ \\ ${ }^{1}$ Ghent University, Department of Molecular Biotechnology, Coupure Links 653, 9000 Ghent, \\ Belgium \\ ${ }^{2}$ Heart Center, University Hospital Ghent, De Pintelaan 185, 9000 Ghent, Belgium \\ ${ }^{3}$ Ghent University, Department of Internal Medicine, De Pintelaan 185, 9000 Ghent, Belgium \\ ${ }^{4}$ Ghent University, Department of Public Health, De Pintelaan 185, 9000 Ghent, Belgium
}

Correspondence

Daisy Vanrompay

daisy.vanrompay@ugent.be

Received 27 March 2009

Accepted 12 May 2009
Chlamydophila psittaci infections in humans are underestimated. We investigated the occurrence of $C$. psittaci in a Belgian population of 540 individuals. Data were from a population survey $(n=2524)$ of apparently healthy community-dwelling subjects aged 35-55 years. Pharyngeal swabs and blood were taken. Individuals completed a questionnaire on professional and nonprofessional activities, smoking habits, medical history and contact frequency with different bird species. Swabs were analysed by a C. psittaci-specific and a Chlamydophila pneumoniaespecific PCR. Sera were tested by a recombinant C. psittaci major outer-membrane proteinbased ELISA, a C. psittaci whole organism-based ELISA (Serion) and a microimmunofluorescence test (Focus Diagnostics). Results confirmed our suspicion about the underestimation of psittacosis in Belgium. Psittaciformes and racing pigeons were the main infection source. Women with excessive alcohol intake defined as a mean intake of $>2$ units daily were more frequently infected than men. We analysed the effect of seropositivity and/or PCR positivity on inflammation (white blood cell count, high-sensitivity C-reactive protein, fibrinogen). In general, seropositivity showed a trend to slightly higher levels of inflammatory variables (all nonsignificant), whilst PCR positivity showed a trend to no effect or even lower inflammatory levels.

\section{INTRODUCTION}

Chlamydophila psittaci can infect humans and should be handled carefully under conditions of bio-containment. Humans most often become infected by inhaling the organism when urine, respiratory secretions or dried faeces of infected birds are dispersed in the air as very fine droplets or dust particles. Other sources of exposure include mouth-to-beak contact, a bite from an infected bird and dissection of dead birds or evisceration in slaughterhouses.

The disease is of public health significance because of the popularity of birds as pets and placement of birds in childcare facilities, garden centres and rest homes. Moreover, feral pigeons in urban habitats are commonly infected, presenting a zoonotic risk (Haag-Wackernagel, 2005;

tPresent address: Pajuheshkadeh, University of Zanjan, PO Box 45195-313, Zanjan, Iran.

Abbreviations: MIF, micro-immunofluorescence; PCR/EIA, PCR enzyme immunoassay; rMOMP, recombinant major outer-membrane protein.
Laroucau et al., 2005; Mitevski et al., 2005). Zoonotic risk is not only limited to direct contact with birds but is also associated with a rural environment and outdoor activities such as gardening and mowing lawns (Fenga et al., 2007; Telfer et al., 2005). Person-to-person transmission is believed to be rare (Hughes et al., 1997; Ito et al., 2002).

The incubation period is 5-14 days. Human infections vary from inapparent to severe systemic disease. The disease is rarely fatal in properly treated patients. Therefore, awareness of the danger and early diagnosis are important. Infected humans typically develop headache, chills, malaise and myalgia. Pulmonary involvement is common.

In Belgium, seven, two and three psittacosis cases were reported in 2005, 2006 and 2007, respectively. In Australia, Germany, Sweden and the Netherlands, 62, 10, 9 and 27 cases were reported in 2007. This is probably an underestimation as psittacosis is difficult to diagnose, is covered by antimicrobials which may be employed empirically for therapy of community-acquired pneumonia, and often is not reported. We therefore examined 
the occurrence of psittacosis in a generally healthy Belgian population in contact with domestic and/or companion birds using a C. psittaci-specific nested PCR and serology. However, because all currently available antibody detection tests are not C. psittaci-specific as they also detect antibodies against Chlamydia trachomatis and Chlamydophila pneumoniae, we also performed a Chlamydia trachomatisspecific ELISA on the C. psittaci-positive sera. Chlamydia trachomatis-positive sera were excluded, although we realized that mixed infections could occur. There is no $C$. pneumoniae-specific antibody ELISA. Therefore, we performed a C. pneumoniae-specific PCR on the pharyngeal swabs of individuals testing positive in the C. psittaci ELISA. C. pneumoniae 'swab positives' were excluded, although we realized that mixed infections could occur. The procedure was used in order to avoid an overestimation of the prevalence of $C$. psittaci in the studied human population.

\section{METHODS}

Study population and samples. Data were from a population survey ( $n=2524)$ of apparently healthy community-dwelling subjects, aged 35-55 years at study initiation, from the communities of ErpeMere and Nieuwerkerken. Subjects were recruited by random sampling of the population database of subjects within the age and geographical constraints. From the first 987 consecutive subjects entering the study (October 2002 until July 2003), pharyngeal specimens were taken using rayon-tipped, aluminium-shafted swabs (Copan). Swabs were provided with DNA stabilization buffer (Roche) and stored at $-80{ }^{\circ} \mathrm{C}$ until tested by PCR. Additionally, blood was collected, and sera were stored at $-80{ }^{\circ} \mathrm{C}$ until serologically tested.

Each participant completed a questionnaire (reviewed by his/her primary care physician and a study nurse at study entry) designed to assess information on professional and non-professional activities, smoking habits, general health, personal medical history, use of medication, and contact with companion and/or domestic animals. In the case of contact with birds, participants defined the bird species and contact frequency. The questionnaire was used to assign participants to groups having (1) daily, (2) weekly, (3) sporadic or (4) no contact with birds. Swabs from 264 male and 276 female participants, 420 having contact with companion/domesticated birds and 120 of 567 randomly chosen participants having no contact with birds, were examined. The ethical committee of Ghent University approved the study and written informed consent was obtained from each subject prior to participating in the study.

PCRs. Pharyngeal DNA as well as positive control DNA (genomic DNA of C. psittaci strain 89/1051 and of C. pneumoniae strain TW183) were prepared as previously described (Harkinezhad et al., 2007). Pharyngeal swabs were tested by a nested PCR enzyme immunoassay (PCR/EIA) which specifically targets the C. psittaci ompA gene (Van Loock et al., 2005). The nested PCR/EIA was performed using external and internal primer pairs generating a biotin-fluorescein dual-labelled ompA product of $451 \mathrm{bp}$, detected by spectrophotometry in streptavidin-coated ELISA plates. Subsequently, C. psittaci PCR/EIA-positive specimens were also examined for the presence of C. pneumoniae by a C. pneumoniaespecific 16S rRNA nested PCR (Messmer et al., 1997) using genusspecific external primers and species-specific internal primers generating PCR products of 436 and $127 \mathrm{bp}$, respectively. Results were visualized by agarose gel electrophoresis.
Serology. Sera of individuals positive by C. psittaci nested PCR/EIA and sera of PCR negatives, but only of PCR negatives having no contact with cats (natural host for Chlamydophila felis) or guinea pigs (natural host for Chlamydophila caviae), were examined. Thus sera of 96 of 471 negatives were analysed using: (1) a micro-immunofluorescence (MIF) test (Focus Diagnostics), detecting IgG and IgA against elementary bodies of C. psittaci genotype A strains 6BC and DD34 from which the lipopolysaccharide (LPS) had been removed; (2) the ELISA classic Chlamydia IgG/IgA (Virion/Serion), detecting antibodies against detergent-extracted elementary bodies of the C. psittaci genotype D Borg strain; and (3) an ELISA detecting IgG and IgM against recombinant major outer-membrane protein (rMOMP) of the genotype A C. psittaci strain 89/1051 (Verminnen et al., 2006).

Tests were performed as advised by the manufacturers diluting sera 1/20 and $1 / 100$ in the Serion ELISA for IgG and IgA detection, respectively. In the MIF test, $1 / 10$ diluted sera were used. The rELISA was performed on twofold serum dilutions (starting at $1 / 100$ ) as previously described (Verminnen et al., 2006). Briefly, rMOMP was produced in pcDNA1::MOMP A-transfected COS-7 cells (Vanrompay et al., 1998). IgG and IgM titres were determined using rMOMP-coated ELISA plates and 1:500 dilutions of horseradish peroxidase-labelled anti-human IgG $(\mathrm{H}+\mathrm{L})$ and anti- $\mu$-chain specific antibodies (Nordic Immunological Laboratories). Results were positive if the absorbance exceeded the cut-off value of the mean of three negative control sera plus two times the standard deviation. Positive control sera originated from three humans infected while visiting a turkey farm experiencing a C. psittaci genotype A infection (Verminnen et al., 2008).

Biochemical analyses. All subjects were fasting, refrained from smoking for at least $6 \mathrm{~h}$, and were screened for active infection/ inflammation. Those with recent or active infection/inflammation were asked to return for blood sampling after their symptoms had subsided for at least 10 days. Serum parameters were measured using commercial reagents on a Modular P system (Roche Diagnostics) in an ISO 9002 certified reference laboratory. High-sensitivity C-reactive protein concentrations were measured by a high-sensitivity, particleenhanced immunoturbidimetric method on an Integra 400 analyser (Roche Diagnostics). Latex particles coated with mouse monoclonal anti-C-reactive protein antibodies were used. Precipitation was determined at $552 \mathrm{~nm}$. The method was standardized with regard to the CRM 470 (RPPHS 91/0619) reference preparation of the International Federation for Clinical Chemistry. The coefficient of variation of all tests was $<3.0 \%$. Excessive alcohol intake was defined as a mean intake of $>2$ units ( 1 unit=one glass of any alcoholcontaining drink) daily for women and $>3$ units daily for men.

Statistics. Potential zoonotic risk factors were analysed by SPSS 15.0.1.1. Logistic regression was used to search for non-exposurerelated risk factors for seropositivity/PCR-positivity. The model contained data on age, gender, body weight, presence of diabetes, excessive alcohol intake, educational achievement, fruit and vegetable intake, hypertension and smoking.

\section{RESULTS AND DISCUSSION}

\section{Contact frequency with bird species}

Based on the questionnaire completed by all 540 participants, 254 (47\%), $58(10.7 \%), 108(20 \%)$ and 120 $(22.2 \%)$ had daily, weekly, sporadic or no contact with birds. In the daily contact group $(n=254)$, most people had contact with canaries $(65.3 \%)$, followed by Psittaciformes $(46.4 \%)$ (Table 1$)$. In the weekly contact group $(n=58)$, most people had contact with racing pigeons $(63.7 \%)$, 
Table 1. Contact frequency with bird species

\begin{tabular}{|lcccc|}
\hline Birds & Daily $(\boldsymbol{n}=\mathbf{2 5 4})$ & Weekly $(\boldsymbol{n}=\mathbf{5 8})$ & Sporadic $(\boldsymbol{n}=\mathbf{1 0 8})$ & Total $(\boldsymbol{n}=\mathbf{4 2 0})$ \\
\hline Canaries & $166(65.3 \%)$ & $35(60.3 \%)$ & $31(28.7 \%)$ & $232(55.2 \%)$ \\
Psittaciformes & $118(46.4 \%)$ & $24(41.3 \%)$ & $32(29.63 \%)$ & $174(41.4 \%)$ \\
Racing pigeons & $58(22.8 \%)$ & $37(63.7 \%)$ & $24(22.2 \%)$ & $119(28.3 \%)$ \\
Ducks & $53(20.8 \%)$ & $14(24 \%)$ & $21(19.4 \%)$ & $90(21.4 \%)$ \\
Geese & $48(19 \%)$ & $21(36.2 \%)$ & $15(13.8 \%)$ & $88(21 \%)$ \\
Turkeys & $24(9.4 \%)$ & $7(12 \%)$ & $11 \%)$ & $46(11 \%)$ \\
\hline
\end{tabular}

followed by canaries $(60.3 \%)$. In the sporadic contact group $(n=108)$, most people had contact with Psittaciformes $(29.63 \%)$, followed by canaries $(28.7 \%)$. Sixty-one, 58.6 and $83.3 \%$ of the participants having daily, weekly or sporadic contact with birds actually had contact with more than one bird species. Participants in contact with only one bird species are presented in Table 2.

\section{PCRs}

Sixty-nine of $540(12.7 \%)$ pharyngeal swabs (44 and 25 of female and male participants, respectively) contained $C$. psittaci DNA. Positives included 57 of 254 (22.4\%), 11 of $58(19 \%), 0$ of $108(0 \%)$ and 1 of $120(0.8 \%)$ persons having daily, weekly, sporadic or no contact with domestic or companion birds, respectively. Thus 471 of $540(87.3 \%)$ examined individuals were negative. Of those, 197 (41.8\%), 47 (10\%), $108(22.9 \%)$ and $119(28.5 \%)$ had daily, weekly, sporadic or no contact with birds, respectively. None of 69 C. psittaci PCR-positive swabs contained C. pneumoniae DNA and all C. psittaci rMOMP ELISA positives were negative in the C. pneumoniae-specific PCR.

\section{Serology}

All 69 C. psittaci PCR-positives and 96 of 471 PCRnegatives (having no contact with cats or guinea pigs) were examined by the rMOMP ELISA, MIF and the Serion Chlamydia ELISA. Twenty-eight of 69 (40.6\%) sera of PCR-positive individuals (21 and 7 of female and male participants, respectively) reacted positively in the rMOMP ELISA. Positive sera originated from 24 and 4 people having daily or weekly contact with domestic or companion birds, respectively. Serum from the single PCR-positive person out of the 'no-contact group' was negative in the rMOMP ELISA. IgG antibody titres ranged from $1 / 100$ to $1 / 400$, while IgM antibody titres were 1/100. Three of 28 $(10.7 \%)$ seropositives had only IgM, indicative of a recent infection, 11 individuals had IgM and IgG, suggesting an ongoing infection, and 14 had only IgG, and regarding the rather low ELISA titres, pointing more in the direction of a past infection. Only 3 of 69 (4.3\%) sera of C. psittaci PCRpositives reacted positively in the MIF test, revealing IgG titres of 16, 64 and 16, respectively, and IgA titres of 16, $<16$ and 32, respectively. The rMOMP ELISA revealed IgG titres of $1 / 100,1 / 100$ and $1 / 200$ in those three sera, respectively. Interestingly, positive control sera were negative in the MIF test. Surprisingly, all 69 C. psittaci PCR-positives were negative in the Serion ELISA while positive control sera contained IgG, but no IgA. Ninety-six of 471 PCR-negatives were assigned to four groups having: (1) daily, (2) weekly, (3) sporadic or (4) no contact with birds. Interestingly, 11 of $43(25.6 \%), 3$ of $8(37.5 \%), 1$ of

Table 2. C. psittaci zoonotic risk related to contact of humans with one single bird species

\begin{tabular}{|c|c|c|c|c|c|}
\hline Contact with: & $\begin{array}{l}\text { No. (\%) of persons from } \\
\text { a total of } 540 \text { examined } \\
\text { in contact with only } \\
\text { one of the bird species }\end{array}$ & $\begin{array}{l}\text { PCR-positives } \\
(\%) \text { in contact } \\
\text { with respectively }\end{array}$ & $\begin{array}{l}\text { PCR and/or ELISA } \dagger \\
\text { positives }(\%) \text { in } \\
\text { contact with } \\
\text { respectively }\end{array}$ & OR $(95 \% \mathrm{CI}) \ddagger$ & $P$-value \\
\hline Psittacine birds & $31(5.7)$ & $7(22.5)$ & $8(25.8)$ & $6.3(2.6-15.2)$ & 0.00001 \\
\hline Parakeet & $23(4.2)$ & $6(26.0)$ & $6(26)$ & $5.9(2.2-15.8)$ & 0.00001 \\
\hline Parrot & $8(1.5)$ & $1(12.5)$ & $2(25)$ & $4.9(1-24.3)$ & 0.050 \\
\hline Racing pigeon & $32(5.9)$ & $7(22)$ & $8(25)$ & $6.0(2.5-14.7)$ & 0.00001 \\
\hline Duck & $2(0.3)$ & $0(0)$ & $0(0)$ & - & - \\
\hline Goose & $5(0.9)$ & $0(0)$ & $0(0)$ & - & - \\
\hline Turkey & $5(0.9)$ & $1(20)$ & $1(20)$ & $3.8(0.43-33.8)$ & 0.23 \\
\hline Total & 144 & 24 & 29 & - & - \\
\hline
\end{tabular}

${ }^{\star}$ Each individual had contact with only one single bird species.

†rMOMP ELISA results.

‡Odds ratio for PCR- and/or ELISA-positives with $95 \%$ confidence intervals. 
$4(25 \%)$ and 3 of $41(7.3 \%)$, thus 18 sera $(18.7 \%)$, of individuals having daily, weekly, sporadic or no contact with birds, respectively, reacted positively in the rMOMP ELISA. Of those 18 positive sera, 9 and 9 were from female and male participants, respectively. The IgG titres ranged from $1 / 100$ to $1 / 400$ while the IgM titres were $1 / 100$. Six of $18(33.3 \%)$ had IgG and IgM, while $1(5.5 \%)$ and 11 (61\%) only had IgM or IgG antibodies, respectively. Sera of 96 PCR-negatives were negative in the MIF test and in the Serion ELISA.

Zoonotic risk related to daily or weekly contact with one single bird species is presented in Table 3 and Table 4, respectively. Sporadic contact with one bird species gave no positives.

\section{Statistics}

Individuals in contact with Psittaciformes (especially parakeets) and racing pigeons were significantly more frequently infected (Table 2). Daily contact with especially racing pigeons and parakeets (Table 3) is significantly more dangerous than contact with canaries. Interestingly, weekly contact with Psittaciformes (Table 4) resulted in a significantly higher infection rate than weekly contact with pigeons or canaries. Thirteen (19\%) of 69 PCR-positives were smokers. However, smoking had no significant effect on acquiring psittacosis. The odds ratio (OR) for the PCRpositives of 41-45 year olds was higher [OR 1.53, 95\% confidence interval (CI) $0.88-2.66 ; P<0.16$ ] than for other age categories (35-40, 46-50 and 51-55 year olds), but was not significantly different regarding the studied population. In a model containing age, body weight, presence of diabetes, excessive alcohol intake, educational achievement, fruit and vegetable intake, hypertension and smoking, nonexposure-related risk factors for seropositivity were gender (OR for women compared to men 2.620, $95 \%$ CI $1.296-$ 5.293; $P<0.007)$ and excessive alcohol intake (OR for excessive vs non-excessive users $2.215,95 \%$ CI 1.084-4.522; $P<0.029)$. Similarly, non-exposure-related risk factors for PCR-positivity were gender (OR for women compared to

Table 3. C. psittaci zoonotic risk related to daily contact with one single bird species

\begin{tabular}{|lcc|}
\hline & $\begin{array}{c}\text { Total no. of persons } \\
\text { in daily contact with } \\
\text { only one of the bird } \\
\text { species }\end{array}$ & $\begin{array}{c}\text { No. of persons } \\
\text { (\%) positive by PCR } \\
\text { and/or rMOMP } \\
\text { ELISA }\end{array}$ \\
\hline Parakeet & 16 & $5(31.2 \%)$ \\
Parrot & 5 & $1(20 \%)$ \\
Canary & 55 & $10(18.2 \%)$ \\
Racing pigeon & 17 & $7(41.2 \%)$ \\
Duck & 1 & $0(0)$ \\
Goose & 3 & $0(0)$ \\
Turkey & 4 & $1(20 \%)$ \\
\hline
\end{tabular}

Table 4. C. psittaci zoonotic risk related to weekly contact with a single bird species

\begin{tabular}{|lcc|}
\hline & $\begin{array}{c}\text { Total no. of persons } \\
\text { in weekly contact with } \\
\text { only one of the bird } \\
\text { species }\end{array}$ & $\begin{array}{c}\text { No. of persons (\%) } \\
\text { positive by PCR } \\
\text { and/or rMOMP } \\
\text { ELISA }\end{array}$ \\
\hline Parakeet & 3 & $1(33.3 \%)$ \\
Parrot & 2 & $1(50 \%)$ \\
Canary & 8 & $2(25 \%)$ \\
Racing pigeon & 9 & $1(11 \%)$ \\
Duck & 0 & $0(0)$ \\
Goose & 1 & $0(0)$ \\
Turkey & 1 & $0(0)$ \\
\hline
\end{tabular}

men 1.942, $95 \%$ CI 1.077-3.501; $P<0.026)$ and excessive alcohol intake (OR for excessive vs non-excessive users $1.705,95 \%$ CI $0.923-3.148 ; P<0.088)$. We analysed the effect of seropositivity and/or PCR positivity on inflammation (white blood cell count, high-sensitivity C-reactive protein, fibrinogen). After adjustment for known confounders, we found no clear significant pattern suggesting an increased inflammatory burden. In general, seropositivity showed a trend to slightly higher levels of inflammatory variables (all non-significant), whilst PCR-positivity showed a trend to no effect or even lower inflammatory levels. We tested whether the subgroup of subjects having at least weekly contact with Psittaciformes had more inflammation (irrespective of PCR or serostatus), but found no evidence of increased inflammatory burden.

\section{Conclusions on the prevalence of $C$. psittaci in humans}

We strongly believed that the annually reported psittacosis cases did not reflect the real C. psittaci infection status in Belgium. Moreover, reports of COST action 855 on animal chlamydiosis and zoonotic implications suggested the underestimation of psittacosis in Europe (www. vetpathology.uzh.ch/forschung/CostAction855/). We therefore examined the prevalence of $C$. psittaci infections in a randomly selected apparently healthy human population sample of East Flanders in contact with domestic and/or companion birds.

Canaries and Psittaciformes, especially parakeets and parrots, were the most popular pet birds, followed by racing pigeons, ducks, geese and turkeys. Individuals in contact with Psittaciformes and racing pigeons were more frequently infected. However, daily contact with Psittaciformes was as dangerous as weekly contact, while weekly contact with racing pigeons was less dangerous than daily contact. This is in accordance with the literature, ascribing most psittacosis cases to contact with Psittaciformes (Heddema et al., 2006a; Kaibu et al., 2006; Smith et al., 2005). A single contact might result in zoonotic transfer (Harkinezhad et al., 2007; Matsui et al., 2008). Psittacosis reports are on severe disease with 
pneumonia and in some cases even cardiac and neurological complications. However, in this study (which was primarily focused on cardiovascular disease and ageing), the main interest of the researchers was chronic inflammation. Those with recent or active infection/inflammation were asked to return for blood sampling after their symptoms had subsided for at least 10 days. Thus no temporal or causal correlation between the presence of chlamydial DNA and clinical respiratory disease can be drawn.

Surprisingly, canaries also seemed to present a substantial zoonotic risk, as 45 of $69(65.2 \%)$ PCR-positives had contact with canaries. However, only $9(20 \%)$ of them had exclusive contact with canaries. Thirty of them $(66.6 \%)$ also had contact with Psittaciformes, while 21 (46.6\%), 16 $(35.5 \%), 16(35.5 \%)$ and $8(17.7 \%)$ also had contact with pigeons, ducks, geese or turkeys, respectively. Thus Psittaciformes, rather than canaries, were more likely responsible for the high number of positives claiming to have contact with canaries. The disease occurs more often in Psittaciformes and the infection is more severe, often leading to bird mortality, as illustrated by Vanrompay et al. (1993) isolating 45 C. psittaci strains from 264 dead birds, among them only four $(8.8 \%)$ isolates of canaries and 25 $(55.5 \%)$ isolates from Psittaciformes. Additionally, over a period of 11 years (1991-2001), Dovc et al. (2005) found 14 of $1677(0.8 \%)$ canaries to be seropositive, compared to 238 of $3869(6.2 \%)$ parrots.

Daily contact with racing pigeons is a serious zoonotic risk. Although not examined, feral pigeons must also present a substantial zoonotic risk as feral pigeons are highly infected (Dovc et al., 2004; Heddema et al., 2006b; Tanaka et al., 2005). In the present study, there was one C. psittaci PCRpositive person not in contact with domestic or companion birds. Maybe zoonotic transfer occurred through contact with feral pigeons or other wild birds. However, the person could also have become infected by human-to-human transmission, although this is extremely rare (Hughes et al., 1997; Ito et al., 2002).

We routinely use the rMOMP ELISA for epidemiology in birds as the test is highly sensitive and specific as compared to LPS- or whole organism-based serological assays (Verminnen et al., 2006). However, birds only become infected with C. psittaci, while humans can become infected with other chlamydial species, with Chlamydia trachomatis and C. pneumoniae being most prevalent. As MOMP carries family-specific epitopes, the presence of $C$. pneumoniae and Chlamydia trachomatis cross-reactive antibodies must be ruled out. We used the Medac ELISA to check for cross-reactive antibodies (data not shown). Only 1 of 28 rMOMP ELISA positives had Chlamydia trachomatis IgA; none had Chlamydia trachomatis IgG. However, the absence of cross-reactive antibodies to C. pneumoniae MOMP cannot be guaranteed, as there is no $C$. pneumoniae-specific antibody detection assay.

The MIF test, long regarded as the serological 'gold standard', is poorly sensitive as only 3 of $69(4.3 \%)$ sera of
PCR-positive individuals reacted positively, and positive control sera remained negative. The MIF test is not chlamydia-specific, due to cross-reaction of chlamydial LPS or heat-shock protein with antibodies to other bacteria (Haralambieva et al., 2001), and like the rMOMP ELISA is not chlamydial species-specific (Bourke et al., 1989; Ozanne \& Lefebvre, 1992). The latter was nicely demonstrated by Ceglie et al. (2007), who found 24 of 34 (70.6\%) pigeon sera positive for both C. psittaci and C. pneumoniae, although birds are not infected by $C$. pneumoniae and molecular characterization of isolates clearly demonstrated the presence of C. psittaci. Additionally, the MIF test is subjective and time-consuming, only semiquantitative and has poor reproducibility (Peeling et al., 2000).

The Serion ELISA is believed to be more sensitive than the MIF. However, this was not the case in our study as none of the 69 C. psittaci PCR-positives reacted positively. This maybe because the Serion ELISA uses genotype D antigen, while MIF uses genotype A. The majority of PCR-positives had contact with Psittaciformes, mostly infected with genotype A. The Serion ELISA uses whole organisms and is not chlamydial species-specific.

In conclusion, C. psittaci-infected racing pigeons and Psittaciformes are the main risk for psittacosis as compared to other domestic and companion birds. Severe disease (occasionally reported after zoonotic transfer) is probably only the tip of the iceberg. What lies underneath are asymptomatic seroconversions or less severe, clinically unnoticed infections, which are misdiagnosed due to symptoms similar to those caused by other respiratory pathogens. The impact of these 'unnoticed' infections on human health is difficult to determine. We also demonstrated the usefulness of a highly sensitive and specific nested PCR/EIA for detecting C. psittaci DNA in human pharyngeal specimens. In general, clinicians should be strongly recommended to use nucleic acid amplification tests for diagnosing psittacosis rather than serology as molecular tests are extremely sensitive and specific and present direct evidence of a C. psittaci infection. Additionally, we also demonstrated the usefulness of serology for epidemiological research, as 18 of 96 PCR-negatives were serologically positive. However, a C. psittaci-specific recombinant or peptide-based ELISA is urgently needed, as present crossreactive tests cannot be used in a human population with $C$. pneumoniae being highly prevalent.

Finally, psittacosis occurs more often in Belgium than reported. The incidence of psittacosis is most likely also underestimated in other European countries, stressing the need for more accurate diagnostic monitoring and reporting, a veterinary vaccine, and information campaigns with recommendations for psittacosis risk-reduction strategies.

\section{ACKNOWLEDGEMENTS}

J. M. Ossewaarde is acknowledged for performing the Serion antibody ELISA. The Federal Department of Health, Food Chain Safety and 
Environment financed this study. The Asklepios research group, financed by the Fund for Scientific Research Flanders, is acknowledged for providing all samples. We gratefully acknowledge the funding by the Fonds voor Wetenschappelijk Onderzoek (research grant G042703, the Asklepios Study).

\section{REFERENCES}

Bourke, S. J., Carrington, D., Frew, C. E., Stevenson, R. D. \& Banham, S. W. (1989). Serological cross-reactivity among chlamydial strains in a family outbreak of psittacosis. J Infect 19, 41-45.

Ceglie, L., Lafisca, S., Guadagno, C., Dalla Pozza, G., Capello, K., Bano, L., Vicari, N., Donati, M., Mion, M. \& other authors (2007). Serological surveillance in north-eastern Italy for the presence of Chlamydophila spp. from birds and molecular characterisation of PCR isolates within the area of Venice. In Proceedings of the 5th Annual Workshop of COST Action 855 Animal Chlamydiosis and Zoonotic Implications, pp. 62-67. Edited by K. Niemczuk, K. Sachse \& L. D. Sprague. Pulawy, Poland: Poland National Veterinary Research Institute.

Dovc, A., Zorman-Rojs, O., Vergles, R. A., Bole-Hribovsek, V., Krapez, U. \& Dobeic, M. (2004). Health status of free-living pigeons (Columba livia domestica) in the city of Ljubljana. Acta Vet Hung 52, 219-226.

Dovc, A., Dovc, P., Kese, D., Vlahovic, K., Pavlak, M. \& Zorman-Rojs, O. (2005). Long-term study of Chlamydophilosis in Slovenia. Vet Res Commun 29 (Suppl. 1), 23-36.

Fenga, C., Cacciola, A., Di Nola, C., Calimeri, S., Lo, G. D., Pugliese, M., Niutta, P. P. \& Martino, L. B. (2007). Serologic investigation of the prevalence of Chlamydophila psittaci in occupationally-exposed subjects in eastern Sicily. Ann Agric Environ Med 14, 93-96.

Haag-Wackernagel, D. (2005). Feral pigeons (Columba livia) as potential source for human ornithosis. In Proceedings of the $3 \mathrm{rd}$ Workshop for Diagnosis and Pathogenesis of Animal Chlamydioses, pp. 15-16. Edited by R. Cevenini \& V. Sambri. Siena, Italy: Bononia University Press.

Haralambieva, I., lankov, I., Petrov, D., Ivanova, R., Kamarinchev, B. \& Mitov, I. (2001). Cross-reaction between the genus-specific lipopolysaccharide antigen of Chlamydia spp. and the lipopolysaccharides of Porphyromonas gingivalis, Escherichia coli $\mathrm{O} 119$ and Salmonella newington: implications for diagnosis. Diagn Microbiol Infect Dis 41, 99-106.

Harkinezhad, T., Verminnen, K., Van Droogenbroeck, C. \& Vanrompay, D. (2007). Chlamydophila psittaci genotype E/B transmission from African grey parrots to humans. J Med Microbiol 56, 1097-1100.

Heddema, E. R., van Hannen, E. J., Duim, B., de Jongh, B. M., Kaan, J. A., van Kessel, R., Lumeij, J. T., Visser, C. E. \& VandenbrouckeGrauls, C. M. (2006a). An outbreak of psittacosis due to Chlamydophila psittaci genotype A in a veterinary teaching hospital. J Med Microbiol 55, 1571-1575.

Heddema, E. R., Ter Sluis, S., Buys, J. A., Vandenbroucke-Grauls, C. M., van Wijnen, J. H. \& Visser, C. E. (2006b). Prevalence of Chlamydophila psittaci in fecal droppings from feral pigeons in Amsterdam, The Netherlands. Appl Environ Microbiol 72, 4423-4425.

Hughes, C., Maharg, P., Rosario, P., Herrell, M., Bratt, D., Salgado, J. \& Howard, D. (1997). Possible nosocomial transmission of psittacosis. Infect Control Hosp Epidemiol 18, 165-168.

Ito, I., Ishida, T., Mishima, M., Osawa, M., Arita, M., Hashimoto, T. \& Kishimoto, T. (2002). Familial cases of psittacosis: possible person-toperson transmission. Intern Med 41, 580-583.
Kaibu, H., lida, K., Ueki, S., Ehara, H., Shimasaki, Y., Watanabe, S., Anzai, H., Takebu, W., Muta, T. \& other authors (2006). Psittacosis in all four members of a family in Nagasaki, Japan. Jpn J Infect Dis 59, 349-350.

Laroucau, K., Mahe, A. M., Bouillin, C., Deville, M., Gandouin, C., Touati, F., Guillot, J. \& Boulouis, H. J. (2005). Health status of freeliving pigeons in Paris. In Proceedings of the 3rd Workshop for Diagnosis and Pathogenesis of Animal Chlamydiosis, pp. 17-18. Edited by R. Cevenini \& V. Sambri. Siena, Italy: Bononia University Press.

Matsui, T., Nakashima, K., Ohyama, T., Kobayashi, J., Arima, Y., Kishimoto, T., Ogawa, M., Cai, Y., Shiga, S. \& other authors (2008). An outbreak of psittacosis in a bird park in Japan. Epidemiol Infect 136, 492-495.

Messmer, T. O., Skelton, S. K., Moroney, J. F., Daugharty, H. \& Fields, B. S. (1997). Application of a nested, multiplex PCR to psittacosis outbreaks. J Clin Microbiol 35, 2043-2046.

Mitevski, D., Pendovski, L. \& Naletoski, I. I. V. (2005). Surveillance for the presence of Chlamydophila psittaci in pigeons and doves from several towns in Macedonia. In Proceedings of the 3rd Workshop for Diagnosis and Pathogenesis of Animal Chlamydiosis, pp. 141-145. Edited by R. Cevenini \& V. Sambri. Siena, Italy: Bononia University Press.

Ozanne, G. \& Lefebvre, J. (1992). Specificity of the microimmunofluorescence assay for the serodiagnosis of Chlamydia pneumoniae infections. Can J Microbiol 38, 1185-1189.

Peeling, R. W., Wang, S. P., Grayston, J. T., Blasi, F., Boman, J., Clad, A., Freidank, H., Gaydos, C. A., Gnarpe, J. \& other authors (2000). Chlamydia pneumoniae serology: interlaboratory variation in microimmunofluorescence assay results. J Infect Dis 181 (Suppl. 3), S426-S429.

Smith, K. A., Bradley, K. K., Stobierski, M. G. \& Tengelsen, L. A. (2005). Compendium of measures to control Chlamydophila psittaci (formerly Chlamydia psittaci) infection among humans (psittacosis) and pet birds, 2005. J Am Vet Med Assoc 226, 532-539.

Tanaka, C., Miyazawa, T., Watarai, M. \& Ishiguro, N. (2005). Bacteriological survey of feces from feral pigeons in Japan. $J$ Vet Med Sci 67, 951-953.

Telfer, B. L., Moberley, S. A., Hort, K. P., Branley, J. M., Dwyer, D. E., Muscatello, D. J., Correll, P. K., England, J. \& McAnulty, J. M. (2005). Probable psittacosis outbreak linked to wild birds. Emerg Infect Dis 11, 391-397.

Van Loock, M., Verminnen, K., Messmer, T. O., Volckaert, G., Goddeeris, B. M. \& Vanrompay, D. (2005). Use of a nested PCRenzyme immunoassay with an internal control to detect Chlamydophila psittaci in turkeys. BMC Infect Dis 5, 76.

Vanrompay, D., Andersen, A. A., Ducatelle, R. \& Haesebrouck, F. (1993). Serotyping of European isolates of Chlamydia psittaci from poultry and other birds. J Clin Microbiol 31, 134-137.

Vanrompay, D., Cox, E., Mast, J., Goddeeris, B. M. \& Volckaert, G. (1998). High-level expression of Chlamydia psittaci major outer membrane protein in COS cells and in skeletal muscles of turkeys. Infect Immun 66, 5494-5500.

Verminnen, K., Van Loock, M., Hafez, H. M., Ducatelle, R., Haesebrouck, F. \& Vanrompay, D. (2006). Evaluation of a recombinant enzyme-linked immunosorbent assay for detecting Chlamydophila psittaci antibodies in turkey sera. Vet Res 37, 623-632.

Verminnen, K., Duquenne, B., De Keukeleire, D., Duim, B., Pannekoek, Y., Braeckman, L. \& Vanrompay, D. (2008). Evaluation of a Chlamydophila psittaci infection diagnostic platform for zoonotic risk assessment. J Clin Microbiol 46, 281-285. 